Check for updates

Cite this: RSC Adv., 2019, 9, 16754

Received 7th February 2019

Accepted 10th May 2019

DOI: $10.1039 / c 9 r a 00996 e$

rsc.li/rsc-advances

\section{Preparation and characterization of multilayered superfine fibrous mat with the function of directional water transport $\uparrow$}

\author{
Jinhao Xu, ${ }^{a}$ Binjie Xin, (DD *a Zhuoming Chen, ${ }^{a}$ Yan Liu, ${ }^{\mathrm{b}}$ Yuansheng Zheng ${ }^{a}$ \\ and Fuli Zhang ${ }^{\mathrm{C}}$
}

Directional water transport in garment materials plays a pivotal role in maintaining human thermal and wet comfort. In the present work, a new type of multilayer fibrous mat with the specific function of directional water transport was prepared via the combination of melt-electrospinning and solutionelectrospinning. The polypropylene (PP) fibrous layer prepared by melt-electrospinning technology was located in the inner layer (next to the skin), while the polyacrylonitrile-containing hydrophilic nano-silica particles $\left(\mathrm{PAN}-\mathrm{SiO}_{2}\right.$ ) layer with remarkable hydrophilicity was located in the outer layer, which could effectively transport water to the outer surface of the composites. Treatment of the asprepared $\mathrm{PAN}-\mathrm{SiO}_{2} / \mathrm{PP}$ with an alkaline aqueous solution of dopamine not only increased the wettability of the PP layer, but also further improved the hydrophilicity of $\mathrm{PAN}-\mathrm{SiO}_{2}$. A layer of cotton woven mesh was added between the TPP layer and TPAN-SiO 2 to form a sandwich structure in order to accelerate water transport in the bilayered fibrous mats. The directional water transport, mechanical flexibility, and permeability of the prepared multilayered superfine fibrous mat were characterized systematically. The experimental results exhibited that TPAN-SiO $/$ cotton mesh/TPP exhibited an excellent accumulative one-way transport index (AOTI, 1071\%), remarkable overall moisture management capacity (OMMC, 0.88), and reasonably high water vapor transport rate (WVT, $11.6 \mathrm{~kg} \mathrm{~d}^{-1} \mathrm{~m}^{-2}$ ), indicating it is a promising candidate for the development of novel textile materials for use in the field of sportswear for fast sweat release applications.

\section{Introduction}

The rapid transport of human sweat has become one of the required functions of textile materials, and thus has attracted increasing attention. ${ }^{\mathbf{1 - 3}}$ If the sweat generated by the human body cannot be transported and released in time, it may remain in the micro-environment and affect the heat and humidity comfort of the human body, causing some related skin diseases. Thus, most commercially available jerseys are woven or knitted using the technique of hydrophilic modification, profiled fibers and post-finishing to endow textiles with the properties of sweat conduction and quick drying. ${ }^{26,32}$ However, these products often have multiple limitations, such as slow wicking rate, complex manufacturing processes and high cost, which restrict their wide application. Based on this, it is particularly significant to

${ }^{a}$ School of Fashion Engineering, Shanghai University of Engineering Science, Shanghai 201620, China.E-mail: xinbj@sues.edu.cn

${ }^{b}$ School of Chemistry and Chemical Engineering, Shanghai University of Engineering Science, Shanghai 201620, China

${ }^{c}$ The Naval Medical I Research Institute, Shanghai 200433, China

$\dagger$ Electronic supplementary information (ESI) available. See DOI: 10.1039/c9ra00996e develop new garment materials with the property of directional water transport. Water is transported to the outer surface of the garment through the fibers and capillary pores in the material. ${ }^{6}$ Janus wettability is an effective water transport mode in porous materials, which is abrupt conduction and relies mainly on the asymmetric water absorption properties of the inner and outer layers to accelerate the rate of transport. ${ }^{7,8}$ According to the above analysis, the inner layer has a relatively hydrophobic and large pore structure, and the outer layer possesses a small pore size with super-hydrophilic properties, which endow the material with remarkable directional water transport performances. For the construction of garment materials with ideal performances, the inner layer may be hydrophobic fibers such as polypropylene fiber (PP) and polyethylene fiber (PET), and polypropylene fine fiber (PAN), polyvinyl alcohol fiber (PVA) and cellulose fibers are ideal for the outer layers. ${ }^{9}$

Electrospinning is an efficient textile processing technology for most polymers for the manufacture of fibrous membranes of various sizes ranging from nanoscale to microscale. ${ }^{\mathbf{1 0}}$ Previously, various types of fibrous materials with excellent directional water transport have been prepared by electrospinning technology (shown in Table below). 


Name
Trilayered fibrous membranes ${ }^{5}$
Cellulose acetate-based
nanofibrous membranes ${ }^{28}$
Nonwoven/Polyacrylonitrile-SiO
nanofiber composite
membranes ${ }^{10}$
Double-layered membranes
constructed of
poly(vinylidenefluoride) fibrous
layer and nylon-6 nanofibrous
layer
Unidirectional water-penetration
composite of hydrophobic
polyurethane and hydrophilic
crosslinked poly (vinyl alcohol)
fibrous layers ${ }^{1}$
Dual-layer electrospun
nanofibrous mats consisting of
polyacrylonitrile layer and
polystyrene layer with and
without interpenetrating
nanopores, respectively

Characteristic

Continuous, spontaneous, and directional water transport Breathable and colorful

Potential candidate for fast sweat release applications Promising candidate for developing modern breathable textiles with enhanced moisture management properties such as sportswear

An interesting "water diode" film is fabricated via a facile electrospinning technique

Tailoring surface hydrophilicity of porous electrospun nanofibers to enhance capillary and push-pull effects for moisture wicking transport and endow the material with outstanding mechanical properties. ${ }^{22}$ Schemes 1 and 2 illustrate the complete preparation process and performance mechanism of the treated PAN$\mathrm{SiO}_{2} / \mathrm{PP}\left(\mathrm{TPAN}_{-} \mathrm{SiO}_{2} / \mathrm{TPP}\right)$ and treated $\mathrm{PAN}-\mathrm{SiO}_{2} /$ cotton mesh/PP (TPAN-SiO $2 /$ cotton mesh/TPP), respectively.

\section{Experimental}

\subsection{Materials}

Polyacrylonitrile (PAN) $\left(M_{\mathrm{w}}=90000\right)$ was purchased from Aladdin Chemicals Co., China. Silica nanoparticles $\left(\mathrm{SiO}_{2} \mathrm{NP}\right.$, 10-50 nm), dopamine hydrochloride $\left(M_{\mathrm{w}}=189.64\right)$, ammonia water, and dimethylformamide (DMF) were purchased from Aladdin Chemicals Co., China. Distilled water was obtained from a Heal-Force water purifying system. Polypropylene (PP, melt index $=16$ ) was purchased from Yousuo Chemical Technology Co., Ltd. cotton mesh $\left(58.16 \mathrm{~g} \mathrm{~m}^{-2}\right)$ was purchased from Jinhai Textile Co., Ltd. The shirt textile, which was only used for the draping and blending test, was a $100 \%$ cotton single jersey $\left(148.64 \mathrm{~g} \mathrm{~m}^{-2}\right)$. All analytical grade chemicals were used as received with no further purification.

\subsection{Preparation of fibrous mats}

Single-layer fibrous mats from polypropylene (PP) were fabricated via melt-electrospinning using a melt-electrospinning machine (MES-001 Laizhou Electronics Co., Ltd.). Before electrospinning, the PP masterbatches were processed into strips by an extruding machine as the as-prepared substance. The asprepared substance was formed by transporting it in a syringe (diameter: $0.4 \mathrm{~mm}$ ) heated to $340{ }^{\circ} \mathrm{C}$ at a speed of $5 \mathrm{~cm} \mathrm{~min}^{-1}$ and fixing it on a slide moving at a speed of $30 \mathrm{~cm} \mathrm{~min}^{-1} \mathrm{~A}$ high direct current voltage of $36 \mathrm{kV}$ was applied between the syringe and the collector, with a distance of $7 \mathrm{~cm}$ maintained between them. The PP fibers were collected on a grounded metallic rotating roller or metallic rotating roller covered cotton mesh at a rotation rate of $45 \mathrm{rpm}$. The relative ambient temperature during the electrospinning was $45^{\circ} \mathrm{C}$. The syringing was in this mode for $0.5 \mathrm{~h}, 1 \mathrm{~h}, 1.5 \mathrm{~h}$ and $2 \mathrm{~h}$ to prepare PP layers with difference thicknesses, which were denoted as PP-0.5, PP-1, PP1.5, and PP-2, respectively.

The spinning solution (100 g) comprised of silica nanoparticles $\left(\mathrm{SiO}_{2} \mathrm{NP}\right)$ concentration $(10 \mathrm{wt} \%$ relative to polymer) and polyacrylonitrile (PAN, $12 \mathrm{wt} \%$ ) was obtained by dissolving the powder reactants in dimethylformamide (DMF) solvent following by magnetic stirring for $8 \mathrm{~h}$. The mixed and uniform solution was electrospun on the surface of PP and cotton meshPP by the needle (diameter: $0.3 \mathrm{~mm}$ ) on an RES-001 Rotary Dynamic Electrospinning Device at a fixed feeding rate of $0.002 \mathrm{~mm} \mathrm{~s}^{-1}$. A high direct current voltage of $20 \mathrm{kV}$ was applied to the needle tip. The fibrous nanofibers were collected on a grounded metallic rotating roller at the same rotation rate $(45$ rpm) covered by PP, cotton mesh-PP, and the needle tip-tocollector distance was maintained at $15 \mathrm{~cm}$. The syringing was conducted in a fixed mode for $3 \mathrm{~h}$ at room temperature and $45 \pm$ $3 \%$ relative humidity. 


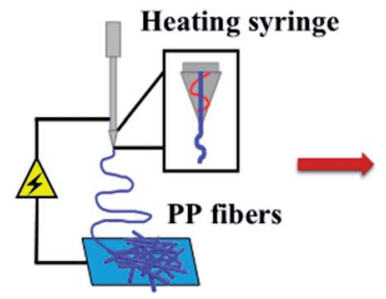

Melt-electrospining

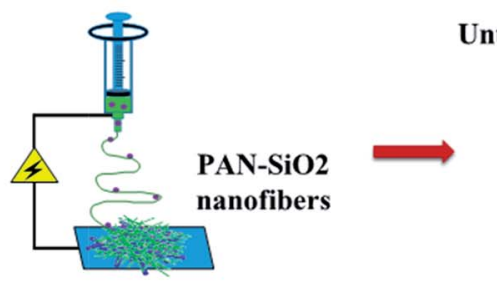

Solution electrospinning
Untreated fibers

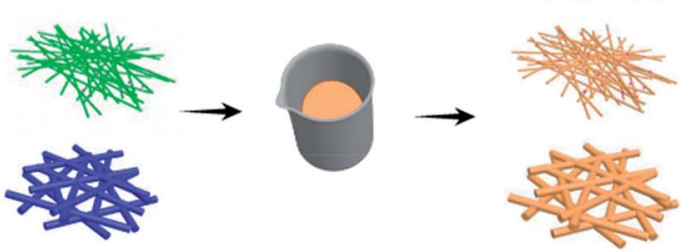

PDOPA coating

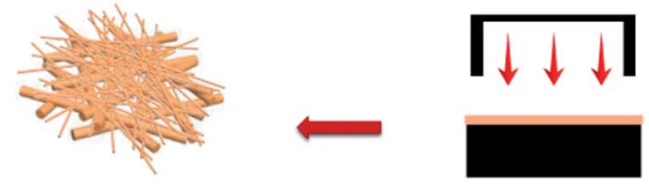

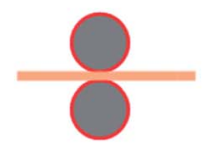

Hot-rolling process

\section{P composite FM.}

\subsection{Treatment with alkaline aqueous solution of dopamine}

Poly-dopamine (PDOPA) was coated on the composite fibrous mats via in situ polymerization. In a typical experiment, ammonia water was dripped into $500 \mathrm{~mL}$ distilled water until the $\mathrm{pH}$ became 8.5 (measured by a $\mathrm{pH}$ tester). A suitable amount of dopamine hydrochloride was weighed to prepared $2 \mathrm{~g} \mathrm{~L}^{-1}$ dopamine alkaline aqueous solution with $8.5 \mathrm{pH}$ ammonia aqueous solution as the solvent, and the mixed solution was magnetically stirred for $15 \mathrm{~min}$ finally. The treatment on the surface of $\mathrm{PAN}_{-} \mathrm{SiO}_{2}$ was conducted for $0.5 \mathrm{~h}, 1 \mathrm{~h}$, and $1.5 \mathrm{~h}$, and the resulting samples were denoted as TPAN-SiO ${ }_{2}-0.5 \mathrm{~h}$, TPAN$\mathrm{SiO}_{2}-1 \mathrm{~h}$, and $\mathrm{TPAN}-\mathrm{SiO}_{2}-1.5 \mathrm{~h}$, respectively. Moreover, the surfaces of $\mathrm{PAN}_{-} \mathrm{SiO}_{2} / \mathrm{PP}$ and $\mathrm{PAN}_{-} \mathrm{SiO}_{2} /$ cotton mesh/PP were treated for $1.5 \mathrm{~h}$ under continuous stirring, and denoted as TPAN-SiO 2 /TPP and TPAN-SiO ${ }_{2} /$ cotton mesh/TPP, respectively. All the treated mats were washed with distilled water three times and dried under vacuum at $60{ }^{\circ} \mathrm{C}$ for $24 \mathrm{~h}$.

\subsection{Characterization}

The morphology of the composite fibrous mats was characterized via scanning electron microscopy (SEM, S-3400N, Japan).

Fourier transform infrared spectroscopy (FTIR) was conducted on a Spectrum Two spectrometer to examine the molecular structure and chemical information of the different treatment time $\mathrm{PAN}-\mathrm{SiO}_{2}$ and $\mathrm{PP}$ samples before and after treatment (PerKin Elmer Inc., USA).

The pore size and pore size distribution of the fibrous membranes were analyzed using a capillary flow porometer (POROLUX 100 FM, Promet Co., Ltd., GER).

The thermal mass loss was investigated using a thermogravimetric analyzer (TGA4000, PerKin Elmer Inc., USA) from $30{ }^{\circ} \mathrm{C}$ to $800{ }^{\circ} \mathrm{C}$ at a heating rate of $30^{\circ} \mathrm{C} \mathrm{min}{ }^{-1}$, which showed the amount of $\mathrm{SiO}_{2}$ in the treated $\mathrm{PAN}_{-} \mathrm{SiO}_{2}$ fibrous membranes.

The contact angles of droplets $(5 \mu \mathrm{L})$ were measured using a contact angle tester (Beijing Jinshengxin Testing Instrument Ltd., China).
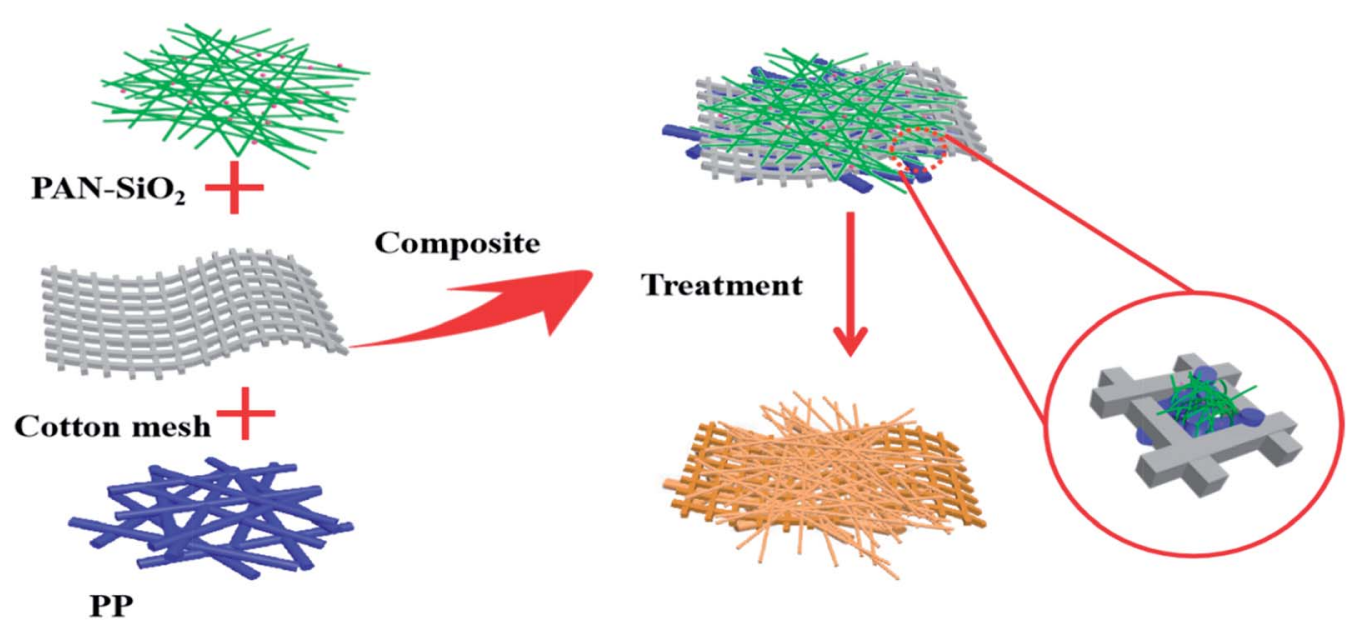

Scheme 2 Illustration of the preparation of TPAN-SiO $2 /$ cotton mesh/TPP with a "sandwich" structure. 
The thickness of each layer of the composite mat was measured using a fabric thickness gauge by applying a certain pressure $(500 \mathrm{~g})$.

A moisture management tester (MMT, SDL ATLAS, Ltd., China) was used to measure the directional water transport performance of the mats. During the test, the sample was placed between two arrays of electric resistance sensors. The transfusion tube in the sensors dripped a fixed concentration of saline water onto the fibrous mats. The probe of the sensors tested the resistance between different rings to reflect the absorption and diffusion of the liquid in the fibrous mats by the change in resistance. The accumulative one-way transport index (AOTI) and over moisture management capacity (OMMC) were calculated as follows:

$$
\mathrm{AOTI}=\frac{\int\left(U_{\mathrm{b}}\right)-\int\left(U_{\mathrm{t}}\right)}{T}
$$

where, $U_{\mathrm{b}}$ is moisture content in the bottom layer, $U_{\mathrm{t}}$ is the moisture content in the top layer and $T$ is the total testing time.

$$
\mathrm{OMMC}=0.25 \mathrm{BAR}+0.5 \mathrm{AOTI}+0.25 \mathrm{BSS}
$$

where, BAR is the bottom absorption rate $\left(\% \mathrm{~s}^{-1}\right)$, AOTC is the accumulative one-way transport index and BSS is the bottom spreading speed $\left(\% \mathrm{~s}^{-1}\right)$.

The tensile strength test was based on GB/T3923.1-2013, with modification. The samples were examined using a testing machine (YG006, China) under a fixed stretching speed of 100 $\mathrm{mm} \min ^{-1}$. The dimensions are fixed parameters $(50 \times 150$ $\mathrm{mm}$ ) and the distance gauge was set to $100 \mathrm{~mm}$.

The water vapor transmission rate test was based on GB/ 21655-2008, with modification. Samples were cut into fixed sizes $(100 \mathrm{~mm} \times 100 \mathrm{~mm})$, and suspended naturally after wetting with water droplets $(0.2 \mathrm{~g})$. The mass of the samples was measured every $5 \mathrm{~min}$.

The wicking height test was based on GB/21655-2008, with modification. The samples were cut into strips $(20 \mathrm{~mm}$ wide $)$ and dipped into distilled water, and the wicking height was recorded every $2 \mathrm{~min}$.

The drape coefficient and blending length were measured using a YG811 fabric drape tester and FAST-2 bending tester, respectively, followed a reported procedure. ${ }^{23,30}$ The drape coefficient was calculated using the following formula:

$$
\mathrm{DC}=\frac{S_{\mathrm{d}}}{S_{\mathrm{O}}} \times 100 \%
$$

where, DC is the drape coefficient, $S_{\mathrm{d}}$ is the area of dropping part and $S_{\mathrm{O}}$ the original area.

Also, the drape stiffness was calculated using the following formula:

$$
\mathrm{BS}=9.81 \times 10^{-8} W L_{\mathrm{B}}{ }^{3}
$$

where, BS is blending stiffness, and $W$ and $L_{\mathrm{B}}$ the sample of unit area quality $\left(\mathrm{g} \mathrm{m}^{-2}\right)$ and blending length $(\mathrm{mm})$, respectively.

The air permeability test was conducted using an automatic permeability meter (YG461E-III, Ningbo Textile Instruments Ltd., China).
The moisture permeability was tested according to GB/ 21655-2008, and the moisture permeability was calculated using the following formula:

$$
\mathrm{WVT}=\frac{24 \times \Delta m}{S}
$$

where, WVT is the moisture permeability, $\Delta m$ is the difference in the mass of water and $S$ is the experimental area of the sample.

\section{Results and discussion}

\subsection{Effect of treatment time for $\mathrm{PAN}_{-} \mathrm{SiO}_{2}$ nanofiber membrane on its hydrophilic property}

$\mathrm{PAN}-S i O_{2}$ nanofibers were modified by hydrolysis and dopamine treatment in alkaline aqueous solution, and subsequently used to prepare nanofiber membranes with superhydrophilic properties (Scheme 3). Fig. 1a-d show the scanning electron microscopy (SEM) images of the $\mathrm{PAN}_{-} \mathrm{SiO}_{2}$ nanofibers membrane, which illustrate the detailed surface morphology obtained by treatment with dopamine alkaline aqueous solution for different times ( $0 \mathrm{~h}, 0.5 \mathrm{~h}, 1 \mathrm{~h}$, and $1.5 \mathrm{~h}$, respectively). It can be seen from the images that the surface of the $\mathrm{PAN}_{-} \mathrm{SiO}_{2}$ fibers became rougher with an increase in treatment time. After treatment for $1.5 \mathrm{~h}$, obvious grooves appeared on the surface of the $\mathrm{PAN}_{-} \mathrm{SiO}_{2}$ fibers, which were formed via the partial hydrolysis of the fibers under the action of hydroxyl radicals $\left(\mathrm{OH}^{-}\right)$in the treatment solution. Moreover, the average pore size of the PAN-SiO ${ }_{2}$ membranes treated with dopamine alkaline aqueous solution was less than that of the untreated nanofibers (1.64 $\mu \mathrm{m})$. When the treatment time was $0.5 \mathrm{~h}$ and $1 \mathrm{~h}$, the average pore size was $0.97 \mu \mathrm{m}$ and $1.1 \mu \mathrm{m}$, respectively. When the treatment time was extended to $1.5 \mathrm{~h}$, the average pore size became $1.54 \mu \mathrm{m}$ (Fig. 2). Although the nanofibers tended to be thin with the prolongation of the treatment time (FS $1 \dagger$ ), which led to an increase in the pore size of the membranes, during the dipping process, the tiny dopamine particles adhered to the surface of the fibrous membranes, making the pore size partially sheltered and reduced. However, when the dipping treatment was $1.5 \mathrm{~h}$, the pore size became large due to the decrease in the diameter of the fibers, which was a more significant factor than the effect of dopamine particles. Fourier transform infrared spectroscopy (FTIR) was used to observe the surface chemical structure (Fig. 3a) of the $\mathrm{PAN}_{-} \mathrm{SiO}_{2}$ nanofibers treated in alkaline dopamine solution for different times. All the spectra showed obvious characteristic peaks at $2246 \mathrm{~cm}^{-1}$, which correspond to the stretching vibration of the nitrile group $(-\mathrm{C} \equiv \mathrm{N})$. After treatment with the alkaline dopamine solution, the characteristic peaks were observed at $1616 \mathrm{~cm}^{-1}$, while the intensity of the peak at $1659 \mathrm{~cm}^{-1}$ gradually decreased. This indicated that hydroxyl $\left(-\mathrm{COO}^{-}\right)$was present in the $\mathrm{PAN}_{-} \mathrm{SiO}_{2}$ nanofiber membranes treated with alkaline dopamine solution. Although the intensity of the peak at $1659 \mathrm{~cm}^{-1}$ gradually weakened with an increase in treatment time, it still showed that amide bonds $\left(-\mathrm{CONH}_{2}\right)$ were present in all the samples. The characteristic peaks at $1088 \mathrm{~cm}^{-1}$ indicated that $\mathrm{SiO}_{2}$ still existed on the surface of the material after treatment. Table 1 


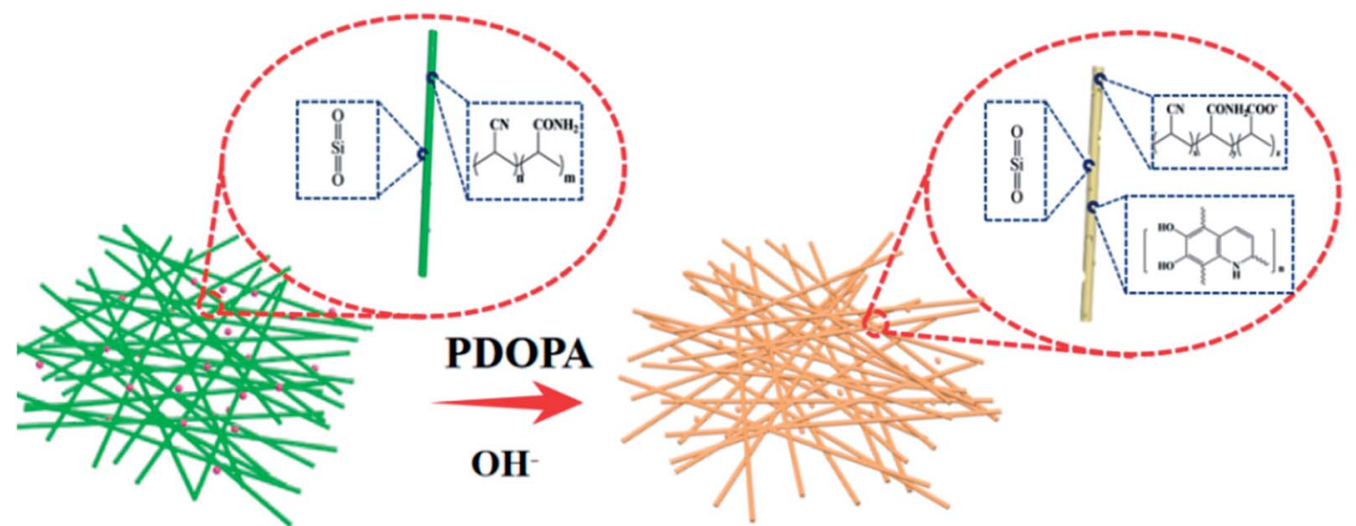

Scheme 3 Illustration of the hydrolysis of the $\mathrm{PAN}-\mathrm{SiO}_{2}$ membrane in alkaline aqueous solution of dopamine.

shows the parameters of $\mathrm{PAN}_{-} \mathrm{SiO}_{2}$ with different treatments time during the thermal decomposition. According to the thermogravimetric analysis (TGA) results and the differential TGA diagram (FS $2 \dagger$ ), the weight residue of the nanofiber membranes tended to decrease with an increase in treatment time, indicating some of the $\mathrm{SiO}_{2}$ nanoparticles fell off the nanofibers. This is because the thermal stability of $\mathrm{SiO}_{2}$ was superior to that of the polymer, ${ }^{34}$ and its surface became rougher. Moreover, after $1.5 \mathrm{~h}$ of treatment, the characteristic peak appeared at around $3350 \mathrm{~cm}^{-1}$, which may be attributed to the stretching vibration of $-\mathrm{OH}$ and $-\mathrm{NH}$, indicating that a certain amount of dopamine was polymerized on the surface of the nanofibers.

The existence of nitrile groups and amide bonds in $\mathrm{PAN}_{-} \mathrm{SiO}_{2}$ nanofibers caused the nanofibers with a rough surface have certain hydrophilic properties. With an increase in the treatment time of the nanofibers in alkaline aqueous solution of dopamine, the wicking height (Fig. 4a) of the nanofibers increased correspondingly, which indicates that the hydrophilicity of the nanofibers was further improved under the action of the stronger hydrophilic chemical groups on the surface and hierarchical micro-nanoscale roughness. ${ }^{\mathbf{5 2 0 , 2 6}}$ When the treatment time was extended to $2 \mathrm{~h}$, the wicking height tended to drop, which is attributed to the increase in the pore size as the fibers became thinner, weakening the wicking effect of the materials (FS $3 \dagger$ ).

It was observed that the wicking height reached about $10 \mathrm{~cm}$ when the $\mathrm{PAN}_{-} \mathrm{SiO}_{2}$ nanofiber membrane was treated in the alkaline aqueous solution of dopamine for $1.5 \mathrm{~h}$; thus, the optimum treatment time for the $\mathrm{PAN}-\mathrm{SiO}_{2}$ nanofiber membrane was fixed at $1.5 \mathrm{~h}$ in subsequent experiments. Simultaneously, the water evaporation rate (Fig. 4b) increased significantly with

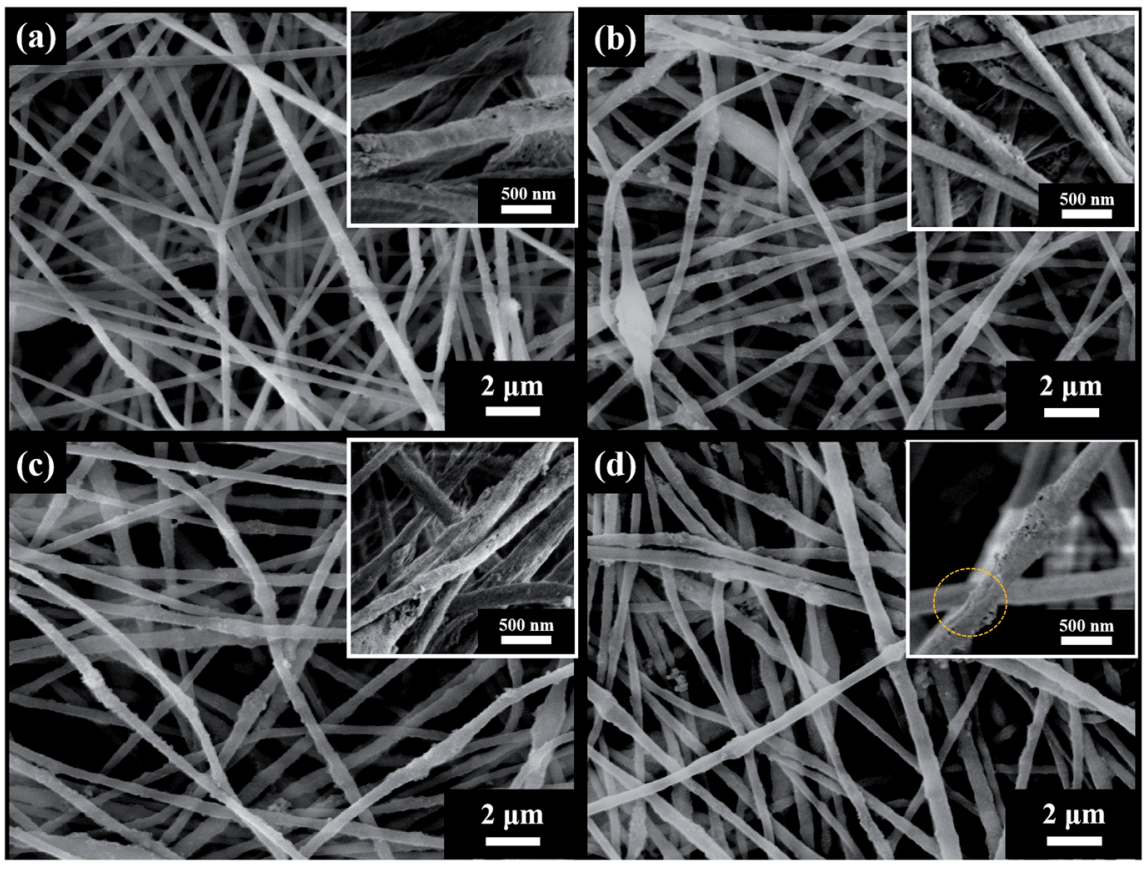

Fig. 1 Microscopic structure of PAN-SiO fiber membranes with different treatment times: (a) $0 \mathrm{~h}$, (b) $0.5 \mathrm{~h}$, (c) $1 \mathrm{~h}$, and (d) $1.5 \mathrm{~h}$. 

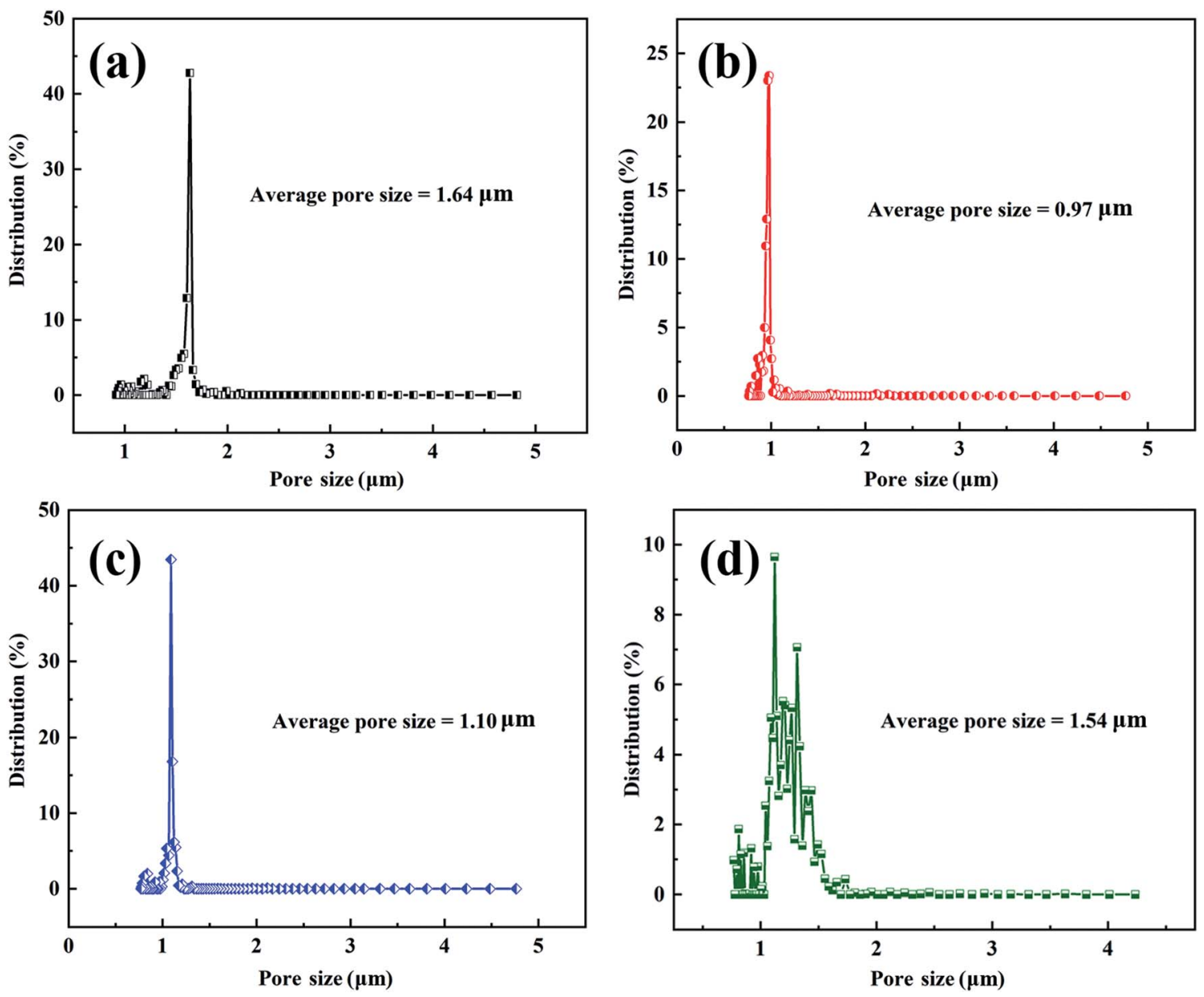

Fig. 2 Pore size distribution of the PAN-SiO fibrous membranes after various alkali treatment times of (a) 0, (b) 0.5 , (c) 1 and (d) $1.5 \mathrm{~h}$.

an increase in the treatment time, indicating the quick drying property of the membranes, which is attributed to the wider wetting area of the hydrophilic nanofiber membrane. ${ }^{25,27}$
Fig. 4c depicts the apparent water contact angle of a droplet on the surface of $\mathrm{PAN}^{-\mathrm{SiO}_{2}}$ nanofibers with different treatment times. The water absorption times for TPAN-SiO ${ }_{2}-0.5$, TPAN$\mathrm{SiO}_{2}-1, \quad \mathrm{TPAN}^{-} \mathrm{SiO}_{2}-1.5$ had no significant difference.
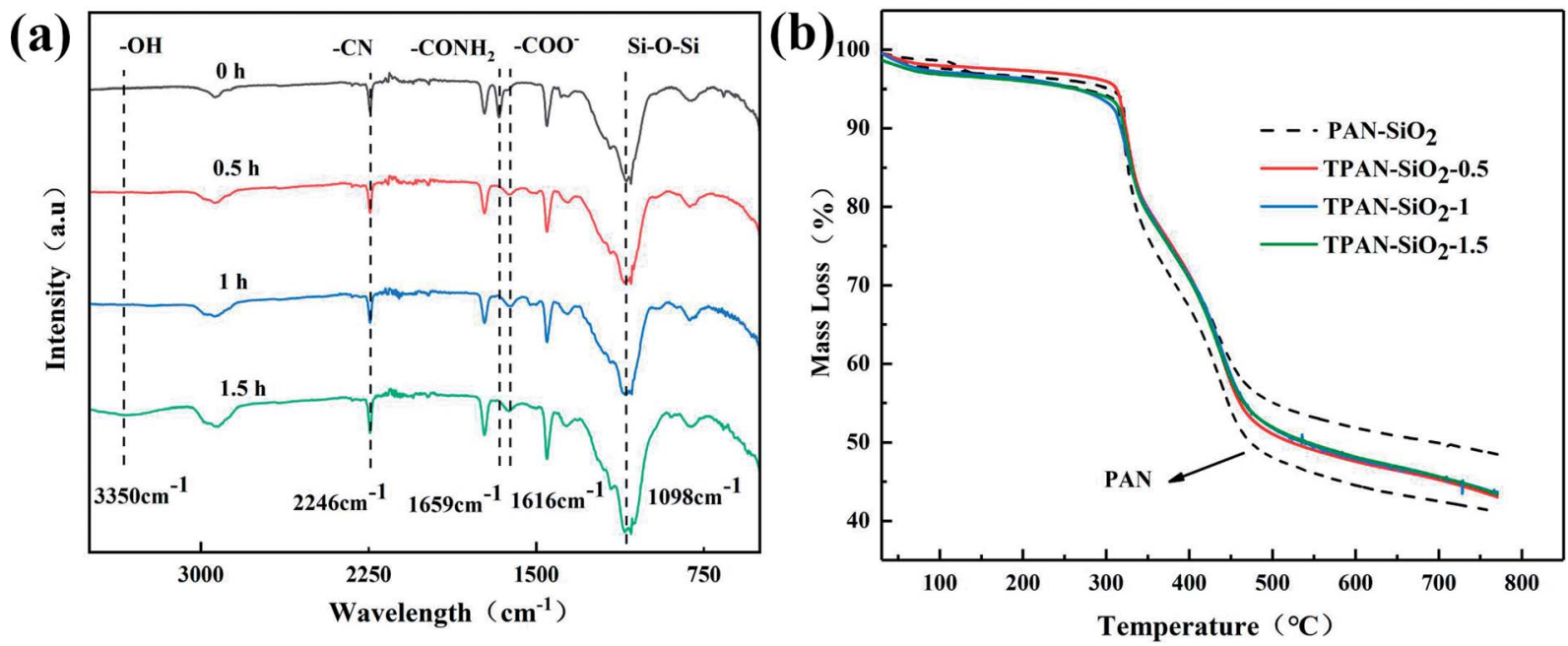

Fig. 3 FTIR spectra (a) and TGA curves (b) of the fibrous membranes. 
Table 1 Parameters of the different samples during the thermal decomposition $^{a}$

\begin{tabular}{|c|c|c|}
\hline Sample & $T_{\mathrm{d}}\left({ }^{\circ} \mathrm{C}\right)$ & $\alpha(\%)$ \\
\hline $\mathrm{PAN} \mathrm{SiO}_{2}$ & 321.6 & 48.5 \\
\hline $\mathrm{PAN} \mathrm{SiO}_{2}-0.5$ & 326.1 & 43.5 \\
\hline $\mathrm{PAN}_{-\mathrm{SiO}_{2}-1}$ & 326.3 & 43.4 \\
\hline $\mathrm{PAN} \mathrm{SiO}_{2}-1.5$ & 326.5 & 43.3 \\
\hline PAN & 324.3 & 39.6 \\
\hline
\end{tabular}

${ }^{a} T_{\mathrm{d}}$ the thermal decomposition temperature at the maximum weight loss rate of material. $\alpha$ weight residue at $800{ }^{\circ} \mathrm{C}$.

Nevertheless, the WCA of $\mathrm{PAN}_{-} \mathrm{SiO}_{2}$ was different from that of the other samples, and the water droplets could be absorbed and diffused completely by the nanofiber membrane after $13 \mathrm{~s}$. This indicated that the hydrophilicity of the PAN nanofibers was enhanced due to the hydrophilic $\mathrm{SiO}_{2}$ nanoparticles $\left(\mathrm{PAN}-\mathrm{SiO}_{2}\right)$. Thus, the nanofiber membranes treated by dopamine alkaline solution contained hydrophilic groups on their surface, and the original hydrophilic $\mathrm{SiO}_{2}$ particles did not completely fall off and still existed, leading to a further improvement in the water absorption on the surface of the membrane. ${ }^{24}$ At the same time, the wettability of the PP layer was also improved in alkali solution of dopamine (FS $4 \dagger$ ).

\subsection{Effect of treatment on water transport behavior in the bilayered fibrous mats}

To investigate the effect of the treatment on the water transport behavior in the bilayered fibrous mats, the change in contact angle with time for the $\mathrm{PAN}-\mathrm{SiO}_{2} / \mathrm{PP}$ bilayered fibrous mats treated at different times ( 0 and $1.5 \mathrm{~h}$ ) was examined (Fig. 5). The initial WCA of PAN-SiO $2 / \mathrm{PP}-0 \mathrm{~h}$ was $130.5^{\circ}$, which was almost the same as that of the single PP layer, and the droplet could not diffuse after $300 \mathrm{~s}$. After the bilayered fibrous mat was treated for $1.5 \mathrm{~h}$ with dopamine alkaline aqueous solution, the initial contact angle of the water droplet decreased to $57.9^{\circ}$ and it was completely absorbed in about $3 \mathrm{~s}$. This phenomenon is attributed to the wettability of the PP layer and the significantly weakened hydrophobicity after dipping in dopamine alkaline aqueous solution. The hydrostatic pressure of the water droplets was greater than the hydrophobicity of the PP layer; thus,
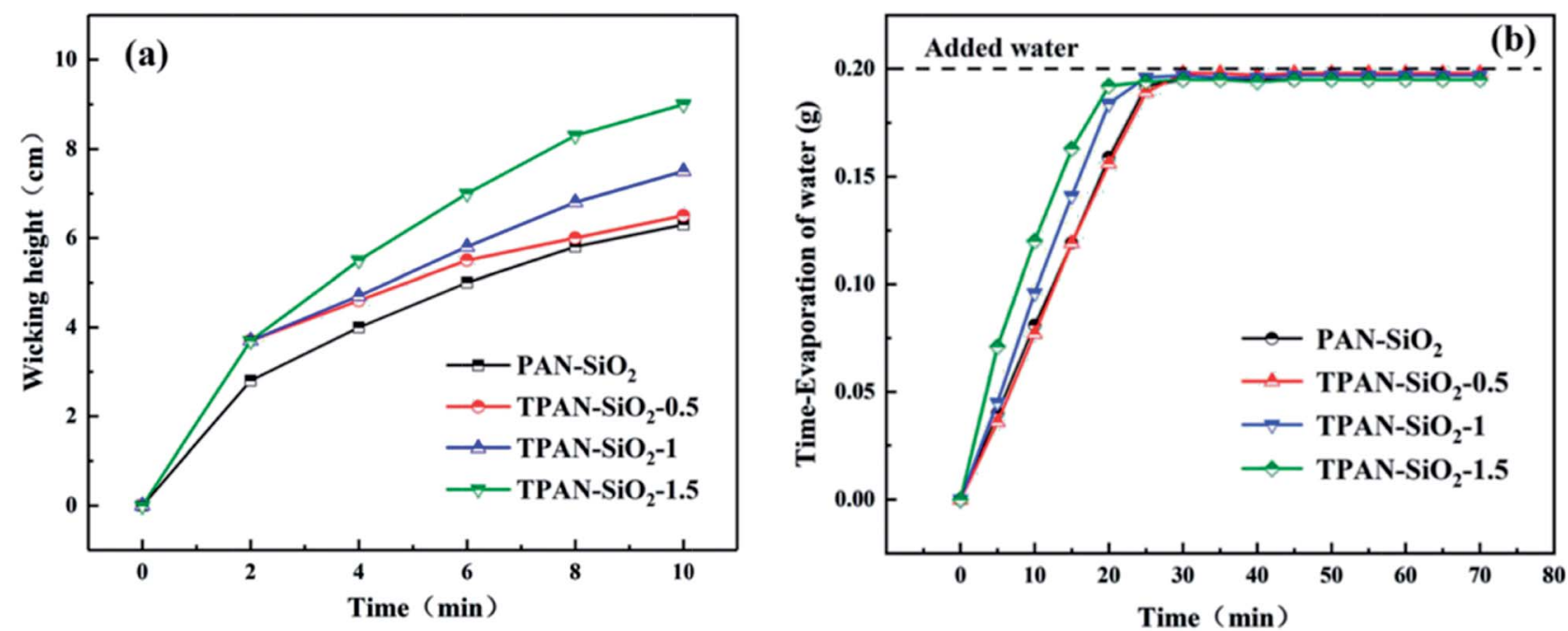

(c)

$\mathbf{0 ~ h}$

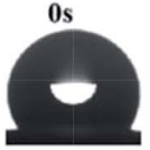

0s

$0.5 \mathrm{~h}$

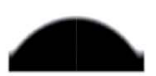

Os

$1 \mathrm{~h}$

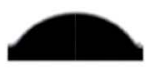

Os

$1.5 \mathrm{~h}$

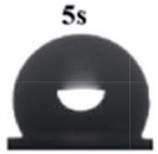

$0.5 s$

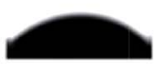

$0.25 \mathrm{~s}$

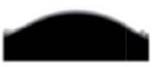

$0.1 \mathrm{~s}$

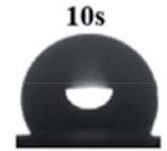

$1 s$

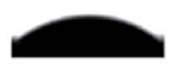

$0.5 s$

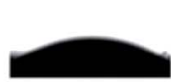

$0.8 \mathrm{~s}$
$11 s$

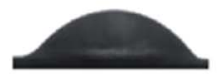

1.5s

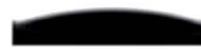

$0.75 s$

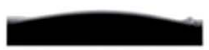

Is

$1.5 \mathrm{~s}$

Fig. 4 Wicking height (a), water evaporation rate (b), and apparent WCA of PAN-SiO 


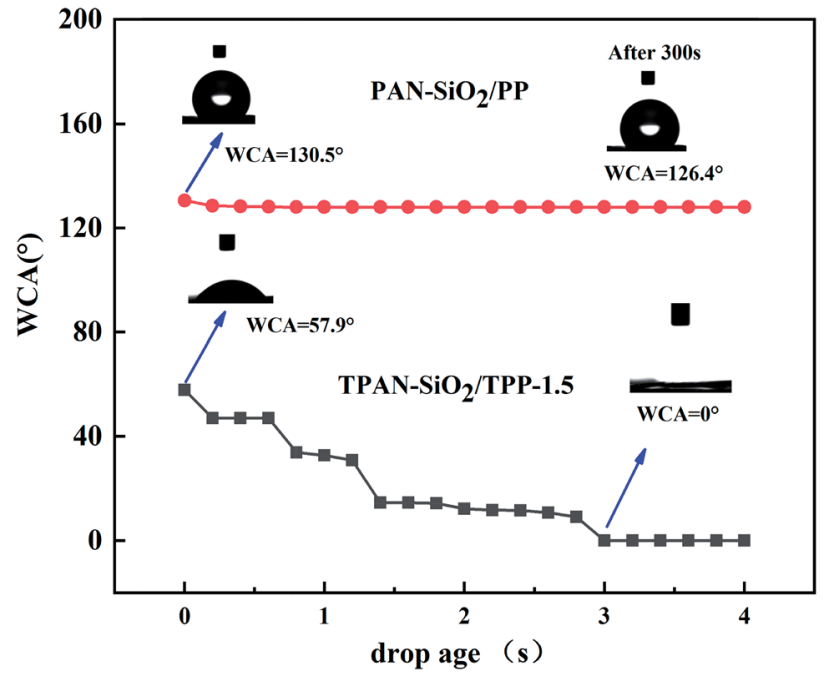

Fig. 5 Apparent WCA of the PAN-SiO 2 /PP bilayered fibrous mats with 0 and $1.5 \mathrm{~h}$ treatment times.

the water droplet could penetrate the PP layer vertically. Meanwhile, the wicking property of the $\mathrm{PAN}_{-} \mathrm{SiO}_{2}$ layer improved, and the water droplet was pulled by the hydrophilic layer quickly.

Fig. $6 \mathrm{a}$ and $\mathrm{b}$ demonstrates the directional water transport of PAN-SiO ${ }_{2} / \mathrm{PP}$ and $\mathrm{TPAN}-\mathrm{SiO}_{2} / \mathrm{TPP}$, which was quantitatively measured using a liquid moisture management tester (MMT). $0.2 \mathrm{~g}$ of saltwater was continuously dropped on the surface of the composite fibrous mats for $120 \mathrm{~s}$. The blue line in the figure represents the relative water content at the top of the mat, while the red line represents the water content at the bottom.

The resultant AOTI value for $\mathrm{PAN}-\mathrm{SiO}_{2} / \mathrm{PP}$ and $\mathrm{TPAN}-\mathrm{SiO}_{2} /$ TPP were $-852 \%$ and $330 \%$, respectively. The water transport behavior was promoted after treatment in alkaline aqueous solution of dopamine due to the improvement in the wettability of the treated PP fibers. The observed images show that when a saltwater droplet was dropped on the $\mathrm{PAN}-\mathrm{SiO}_{2} / \mathrm{PP}$, the majority of water stayed on the surface of the PP layer and hardly transported to the opposite side. This is because the surface energy was so small that the PP layer was endowed with strong hydrophobic property; hence, the water droplet could not contact the hydrophilic layer $\left(\mathrm{PAN}^{-} \mathrm{SiO}_{2}\right)$ and pulled out by capillary. However, the water content at the bottom was significantly larger than that at the top when a certain amount of water was dropped on TPAN-SiO ${ }_{2} / \mathrm{TPP}$. Initially, the water content at the top increased faster than that at the bottom, and reached the maximum at the point of $10 \mathrm{~s}$. This is attributed to the relatively strong initial hydrophobic force on the TPP side, which slowed the downward transport of water droplets. The water content at the bottom of the layer increased steadily with time and exceeded that at the top at the end of $37 \mathrm{~s}$ owing to the water being pulled out by the $\mathrm{TPAN}-\mathrm{SiO}_{2}$ layer under the remarkable wicking action, which accelerated the rate of wetting in the bottom area. The bottom water content did not increase significantly after $80 \mathrm{~s}$, and remained at a stable level. Nevertheless, when the composite mat was reversed and the saltwater droplet was added to the $\mathrm{TPP}-\mathrm{SiO}_{2}$ side, all the water accumulated at the top without transporting downwards, making the bottom hardly wetted (FS 5a†).

When a suitable amount transparent blue ink droplets (35 $\mu \mathrm{L}$ ) was on the TPP side, it was observed that the water was quickly transported from the TPP layer to the opposite side (Fig. 7a and b), showing the excellent wettability on the TPP side and capillary force on the $\mathrm{TPAN}-\mathrm{SiO}_{2}$ side. Also, it was observed that the water spreading area on the TPP side was small, because of a large amount of water was absorbed by TPAN-SiO and diffused along the transverse direction. Thus, the experimental results prove that TPP has decent water transport ability and did not absorb the water, which meets the requirements of quick drying of inner layer to ensure thermal and humid comfort for the human body. $\mathrm{TPAN}^{-\mathrm{SiO}_{2}}$ had remarkable wicking ability, and it could pull water out quickly and accelerate the rate of water transport. However, when water was
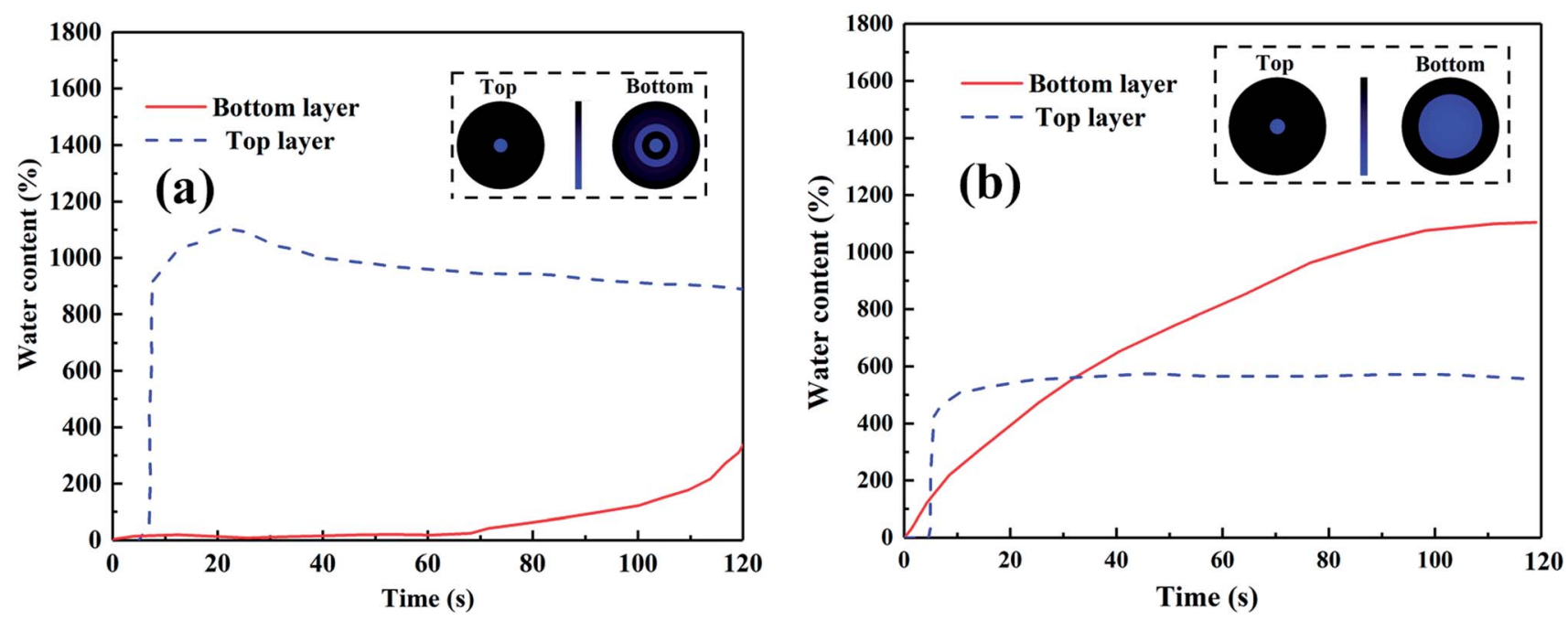

Fig. 6 MMT results of the PAN-SiO $/ \mathrm{PP}$ bilayered fibrous mats with (a) 0 and (b) $1.5 \mathrm{~h}$ treatment time. 

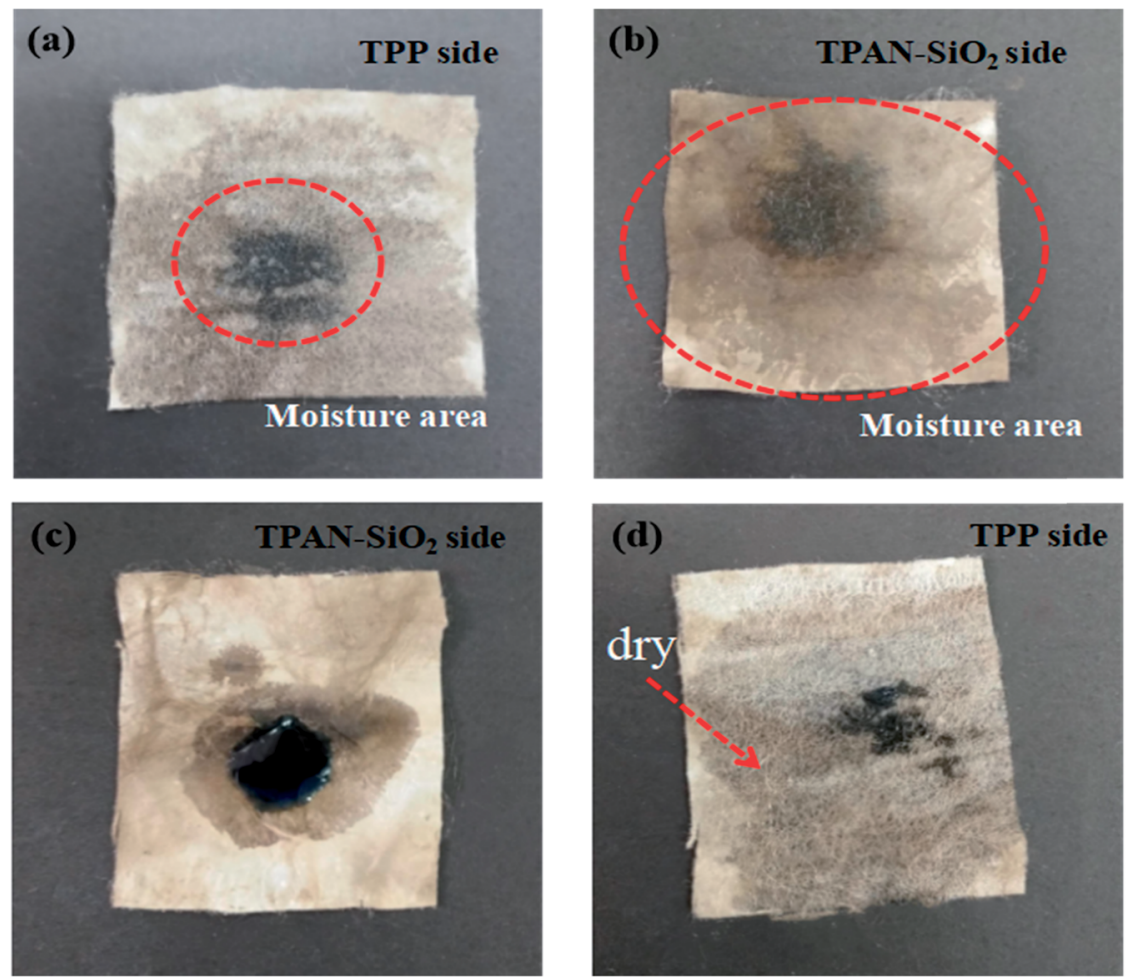

Fig. 7 Photographs showing the water spreading and transport abilities of the bilayered fibrous mats. Illustration of the directional water transport mechanism: Water is dropped on the TPP side ( $a$ and b) and TPAN-SiO 2 side (c and d).

dropped in the opposite direction (Fig. 7c and d), water accumulated on the surface of TPAN-SiO ${ }_{2}$ and diffused rapidly along the transverse plane, while only a small amount of water was transported to the other side; thus, most areas of the TPP side remained dry. This phenomenon intuitively demonstrates that TPAN-SiO ${ }_{2} / \mathrm{TPP}$ has outstanding directional water transport.

\subsection{Effect of PP layer thickness on water transport behavior in the multilayered superfine fibrous mats}

Multilayered superfine fibrous mats were prepared with different PP layer thicknesses by controlling the meltelectrospinning time, as shown in Table 2, and the effect of thickness on their directional water transport behavior was investigated.
Fig. 8a-d present the water transport behavior and quantitative analysis of the amount of water retained in the top and bottom layers of $\mathrm{TPAN}-\mathrm{SiO}_{2} /$ cotton mesh/TPP with various thicknesses. The resultant AOTI values for the obtained multilayered superfine fibrous mats were $861 \%, 1071 \%, 841 \%$, and $352 \%$. The water content in the TPP layer in $\mathrm{TPAN}-\mathrm{SiO}_{2} /$ cotton mesh/TPP-1 was almost zero and the hydrophilic layers of all the samples were completely wetted by water after the cotton mesh was sandwiched, which indicate the cotton mesh acts as a transfer layer to accelerate water transport.

When the time of melt-spinning was $0.5 \mathrm{~h}$, the thickness of the PP layer was $0.11 \pm 0.01 \mathrm{~mm}$. At this time, the water droplet experienced a weaker hydrophobic force because the PP layer was relatively thin. Thus, the water droplet could easily pass through the hydrophobic layer and be absorbed by the

Table 2 The thickness of every single layer and multilayered superfine fibrous mats with different melt-electrospinning times

\begin{tabular}{|c|c|c|}
\hline Sample & Sample ID & Average thickness (mm) \\
\hline \multirow[t]{5}{*}{ Single-layer sample } & $\mathrm{TPAN}_{-} \mathrm{SiO}_{2}$ & 0.074 \\
\hline & Cotton mesh & $0.33 \pm 0.02$ \\
\hline & TPP-1 & $0.34 \pm 0.03$ \\
\hline & TPP-1.5 & $0.54 \pm 0.03$ \\
\hline & TPP-2 & $0.71 \pm 0.04$ \\
\hline & $\mathrm{TPAN} \mathrm{SiO}_{2} /$ cotton mesh/TPP-1.5 & $0.93 \pm 0.01$ \\
\hline & $\mathrm{TPAN} \mathrm{SiO}_{2} /$ cotton mesh/TPP-2 & $1.15 \pm 0.03$ \\
\hline
\end{tabular}



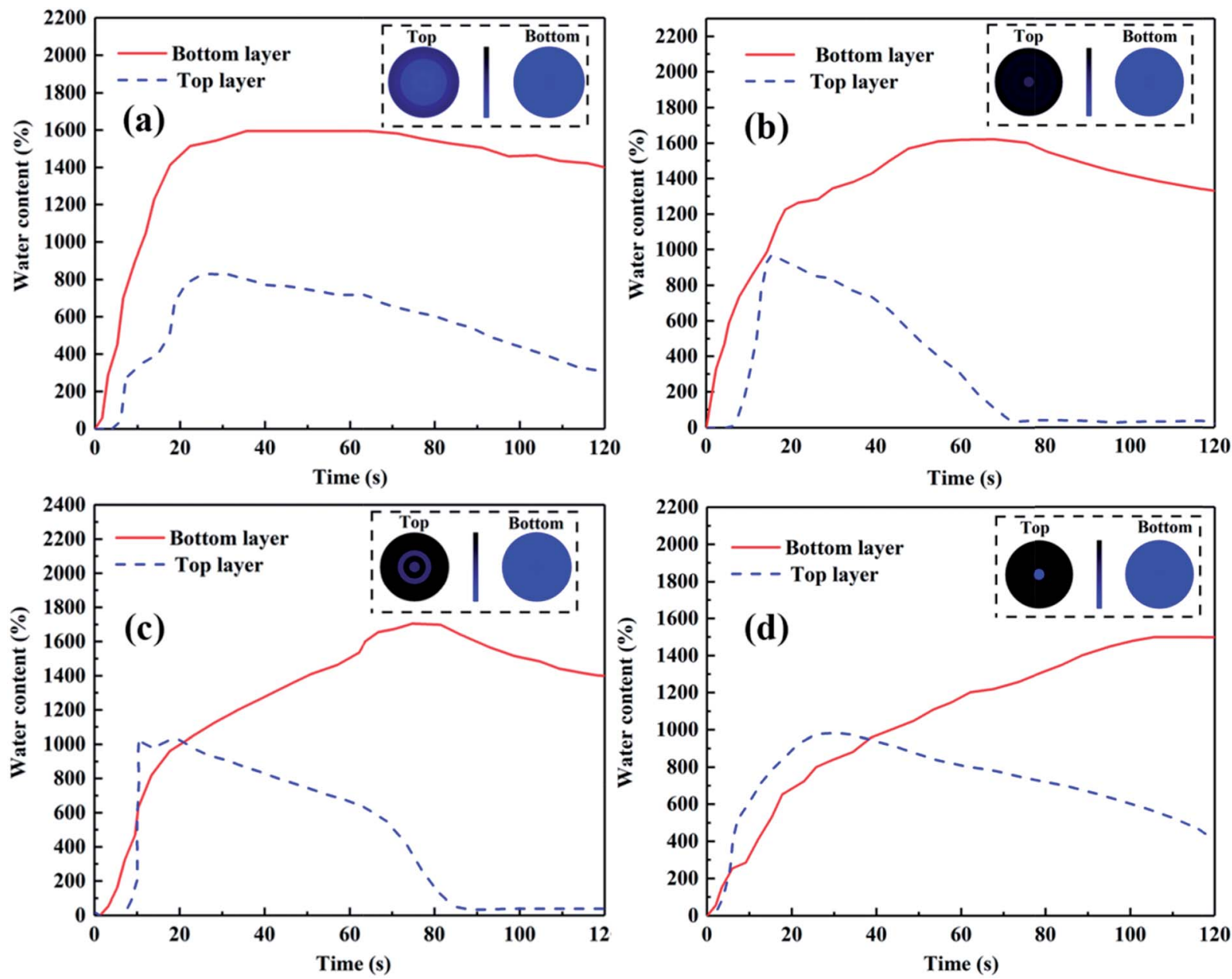

Fig. 8 MMT results for the TPAN- $\mathrm{SiO}_{2} /$ cotton mesh/TPP with the $0.5 \mathrm{~h}(\mathrm{a}), 1 \mathrm{~h}$ (b), $1.5 \mathrm{~h} \mathrm{(c),} 2 \mathrm{~h}$ (d) melt-electrospinning time.

hydrophilic side. However, the water droplet easily diffused transversely under the action of the cotton mesh in this case, making the PP layer wetted and affecting the directional water transport of the material, as shown in Fig. 8a. When the spinning time was extended to $1 \mathrm{~h}$, the thickness of the PP layer reached $0.34 \pm 0.03 \mathrm{~mm}$. The water droplets could be absorbed by the outer layer and the inner layer kept the dry state for $120 \mathrm{~s}$, showing an excellent water transport effect, as shown in Fig. 8b. Moreover, the composites still exhibited an excellent wearability performance (FS 6 and FS $8 \dagger$ ). ${ }^{35}$ Continuous prolongation of the spinning time to $1.5 \mathrm{~h}$ and $2 \mathrm{~h}$ caused the thickness of the PP layer to increase constantly. The water droplet was subjected to a greater hydrophobic force in the inner layer, which limited the transport of water in the material, thus affecting the overall performance of the directional water transport (Fig. 8c and d, respectively).

\subsection{Directional water transport mechanism in the multilayered superfine fibrous mat}

Based on the above results, we discuss the mechanism of directional water transport. As illustrated in Fig. 9a, when a water droplet was dropped on the hydrophobic layer side (TPP side), the droplet was subjected to two opposite forces, namely, hydrostatic pressure (HP) and hydrophobic force (HF). HF impeded the downward transport of the droplet to wet the fibrous mat, and the effect of HF was related to the nature of the water itself, being proportional to the weight of the droplet. When the HP was larger than the HF, the droplet would penetrate the hydrophobic layer and contact the hydrophilic layer (TPAN-SiO ${ }_{2}$ side), which would be accelerated by the capillary force provided by the hydrophilic layer (TPAN-SiO ${ }_{2}$ side). When the droplet was dropped on the other layer ( $\mathrm{TPAN}-\mathrm{SiO}_{2}$ side), the water droplet would absorb and transverse diffuse quickly on its surface. After the water droplet reached the contact plane between the two layers, the hydrophobic force of the opposite hydrophobic layer (TPP side) would prevent the water from continuing to penetrate the other side, thus effectively reducing the wetting area of the hydrophobic layer (next to the skin)..$^{29,31}$

Fig. $9 \mathrm{~b}$ depicts the mechanism of directional water transport in the multilayered superfine fibrous mat. When the water droplet was dropped on the hydrophobic side, it still retained a Wenzel-Cassie state subjected to two forces in opposite directions, hydrostatic pressure (HP) and hydrophobic force (HF), which is the same as mechanism in the bilayered fibrous 
(a) From hydrophobic side

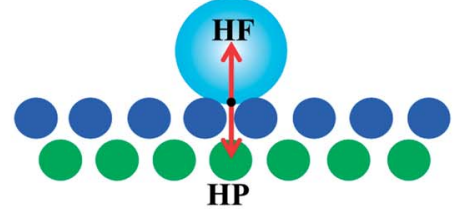

From hydrophilic side
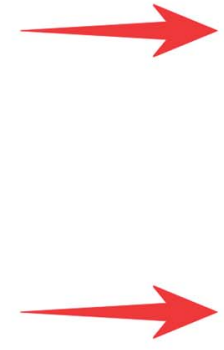
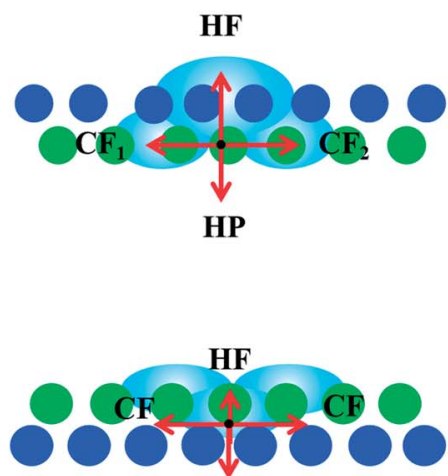

HP

TPAN-SiO2 TPP

HP:Hydrostatic Pressure

HF:Hydrophobic Force CF:Capillary Force

(b) From hydrophobic side

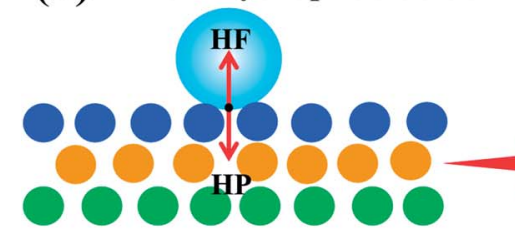

From hydrophilic side

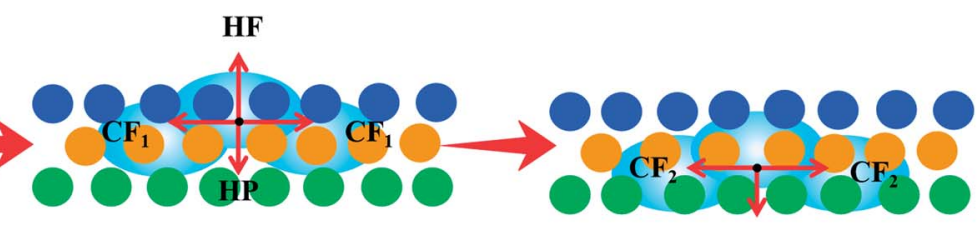

HP

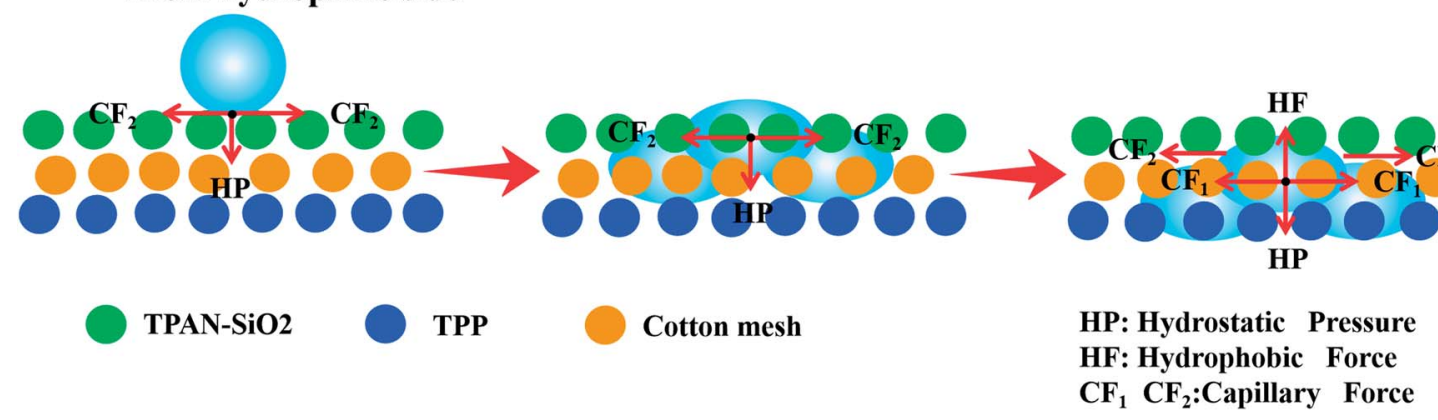

Fig. 9 Illustration of the directional water transport mechanism in the bilayered fibrous mats (a) and multilayered superfine fibrous mats (b): water is dropped on the upward hydrophobic TPP side and $\mathrm{TPAN}-\mathrm{SiO}_{2}$ side, respectively.

mats. When the water droplet moved downward, it would be continuously attracted by the capillary force $\left(\mathrm{CF}_{1}\right.$ and $\left.\mathrm{CF}_{2}\right)$ provided by the cotton mesh and $\mathrm{TPAN}-\mathrm{SiO}_{2}$ successively, resulting in progressive wettability to speed up the water droplet transport to the opposite side, thus increasing the diffusion area of water on the hydrophilic side, as shown in the inserted images in Fig. 6 and 8. On the other hand, when the water droplet was on the hydrophilic layer side, it would be absorbed rapidly by the cotton mesh and $\mathrm{TPAN}^{-\mathrm{SiO}_{2}}$ and diffuse horizontally. When water droplets contacted the TPP layer, they suffered from hydrophobic force in the upward direction, preventing the block inner layer from being wetted. Interestingly, insignificant areas of the inner layer in TPAN-SiO $/$ cotton mesh/ TPP were wetted by water due to the close combination of PP fibers and cotton mesh under the action of electrostatic force (FS 5b†), but large areas remained dry in the TPP layer.

\section{Conclusion}

In summary, the TPAN-SiO ${ }_{2} /$ cotton mesh/TPP multilayered superfine fibrous mat prepared by dual-mode electrospinning technology and subsequent treatment meets two types of water transport requirements for materials used in the field of functional textiles. The wettability of its inner layer and hydrophilicity of its outer layer were improved by dipping it in a dopamine alkaline aqueous solution, which weakened the initial hydrophobic force for water transport. Through MMT test, the multilayered superfine fibrous mats exhibited obvious directional water transport ability, exhibiting outstanding AOTI $(1071 \%)$ and excellent OMMC (0.88) values, and when they were flipped, the AOTI value changed to $-1332 \%$, exhibited a reasonable performance of water directional water transport. The TPAN-SiO ${ }_{2} /$ cotton mesh/TPP multilayered superfine fibrous 
mat exhibited decent strength and excellent permeability while remaining soft, which give it further practical application value.

Interestingly, in during the experiment, we found that when spinning the PP fiber layer by melt-electrospinning with cotton mesh as the substrate, the PP fibers and cotton yarn were attached relatively close due to the electrostatic force interaction between them. The cellulose fiber also had good hydrophilicity, which meets the requirement of directional water transport. Thus, we will subsequently conduct in-depth research on this material.

\section{Conflicts of interest}

There are no conflicts to declare.

\section{Acknowledgements}

This work was supported by the National Natural Science Foundation of China (Grant No. 11702169), Scientific Research Staring Foundation of Shanghai University of Engineering Science (Grant No. 2017-19), and Talents Action Program of Shanghai University of Engineering Science (Grant No. 2017RC522017). This work was also supported by Talents Action Program of Shanghai University of Engineering Science (Grant No. 2017RC432017).

\section{References}

$1 \mathrm{~J}$. Wu, W. Nü and L. Wang, Unidirectional water-penetration composite fibrous film via electrospinning, Soft Matter, 2012, 8, 5996.

2 Y. Dong, J. Kong and S. L. Phua, Tailoring surface hydrophilicity of porous electrospun nanofibers to enhance capillary and push-pull effects for moisture wicking, ACS Appl. Mater. Interfaces, 2014, 6, 14087.

3 S. F. Ming, M. J. Zi and T. Jian-Wei, Research on hot-wet comfort of triangle-hollow polyamide seamless knitted fabric, Silk, 2011, 15-17.

4 Y. Xu, D. Wang and M. Zhang, Self-layering behavior of PET fiber deposition in melt-electrospinning process, Fibers Polym., 2017, 18, 1981-1987.

5 Y. M. Dong., H. Zhan. and F. W. Xian., Continuous, Spontaneous, and Directional Water Transport in the Trilayered Fibrous Membranes for Functional Moisture Wicking Textiles, Small, 2018, 180, 1527.

6 M. Yao, M. W. Shi and S. Z. Jiang, Research on the theory and practice of fabric wet conduction Part I: Study on the process and structure of fabric wet conduction, J. Xi'an Univ. Eng. Sci. Technol., 2001, 15, 1-8.

7 X. Tian, J. Li and X. Wang, Anisotropic liquid penetration arising from a cross-sectional wettability gradient, Soft Matter, 2012, 8, 2633-2637.

8 J. E. Mates, T. M. Schutzius and J. Qin, The Fluid Diode:Tunable Unidirectional Flow through Porous Substrates, ACS Appl. Mater. Interfaces, 2014, 6, 12837-12843.
9 Y. N. Chen and Mu. Yao, Requirements of Hygroscopic/ Quick-drying Functional Fabrics on Fabric Structure, J. Xi'an Univ. Eng. Sci. Technol., 2017, 15, 14-16.

10 A. A. Babar, X. Wang and N. Iqbal, Tailoring Differential Moisture Transfer Performance of Nonwoven/ Polyacrylonitrile-SiO ${ }_{2}$ Nanofiber Composite Membranes, Adv. Mater. Interfaces, 2017, 4, 1700062.

$11 \mathrm{~J}$. Lyons and F. Ko, Feature. Article. Melt Electrospinning of Polymers:A Review, Polym. News, 2005, 30, 170-178.

$12 \mathrm{~J}$. Lyons, C. Li and F. Ko, Melt-electrospinning part I: processing parameters and geometric properties, Polymer, 2004, 45, 7597-7603.

13 Y. Li, Z. Zhu and J. Yu, Carbon Nanotubes Enhanced Fluorinated Polyurethane Macroporous Membranes for Waterproof and Breathable Application, ACS Appl. Mater. Interfaces, 2015, 7, 13538-13546.

14 S. Lee and S. K. Obendorf, Developing protective textile materials as barriers to liquid penetration using meltelectrospinning, J. Appl. Polym. Sci., 2006, 102, 3430-3437.

15 R. Nayak, I. L. Kyratzis and Y. B. Truong, Meltelectrospinning of polypropylene with conductive additives, J. Mater. Sci., 2012, 47, 6387-6396.

16 Y. Liu, X. Wang, H. Yan, C. Guan and W. Yang, Dissipative particle dynamics simulation on the fiber dropping process of melt electrospinning, J. Mater. Sci., 2011, 78777882.

17 T. Xu, J. Yu and Z. H. Jin, Effect of melt fluidity on crystallinity and mechanical properties of polypropylene materials, China Plast., 2000, 5, 29-75.

18 C. Li, Su. Morphology, crystallization behavior and tensile properties of $\beta$-nucleated isotactic polypropylene fibrous membranes prepared by melt electrospinning, Chin. J. Polym. Sci., 2014, 32, 1167-1175.

19 R. Nayak, I. L. Kyratzis and Y. B. Truong, Meltelectrospinning of polypropylene with conductive additives, J. Mater. Sci., 2012, 47, 6387-6396.

20 P. C. Hsu, A. Y. Song and P. B. Catrysse, Radiative human body cooling by nanoporous polyethylene textile, Science, 2016, 353, 1019-1023.

21 H. Lee, S. M. Dellatore and W. M. Miller, Mussel-Inspired Surface Chemistry for Multifunctional Coatings, Science, 2007, 318, 426-430.

$22 \mathrm{H}$. Yang, Y. Lan and W. Zhu, Polydopamine-coated nanofibrous mats as a versatile platform for producing porous functional membranes, J. Mater. Chem., 2012, 22, 16994-17001.

23 M. L. Gupta, B. Gupta and W. Oppermann, Surface modification of polyacrylonitrile staple fibers via alkaline hydrolysis for superabsorbent applications, J. Appl. Polym. Sci., 2004, 91, 7.

24 B. Su, Y. Tian and L. Jiang, Bioinspired Interfaces with Superwettability: From Materials to Chemistry, J. Am. Chem. Soc., 2016, 138, 1727.

25 G. Havenith, P. Brode and E. D. Hartog, Evaporative cooling: effective latent heat of evaporation in relation to evaporation distance from the skin, J. Appl. Physiol., 2013, 114, 778-785. 
26 M. Zaman, H. Liu and H. Xiao, Hydrophilic modification of polyester fabric by applying nanocrystalline cellulose containing surface finish, Carbohydr. Polym., 2013, 91, 560-567.

27 J. H. Jiang, L. P. Zhu and X. L. Li, Surface modification of PE porous membranes based on the strong adhesion of polydopamine and covalent immobilization of heparin, $J$. Membr. Sci., 2010, 364, 194-202.

28 B. A. Ahmed, Y. M. Dong and A. Nadir, Breathable and Colorful Cellulose Acetate-Based Nanofibrous Membranes for Directional Moisture Transport, ACS Appl. Mater. Interfaces, 2018, 10, 22866-22875.

29 J. Wu, N. Wang, L. Wang, H. Dong, Y. Zhao and L. Jiang, Unidirectional water-penetration composite fibrous film via electrospinning, Soft Matter, 2012, 8, 5996.

30 Z. Q. Du, T. Zhou and N. Yan, Measurement and characterization of bending stiffness for fabrics, Fibers Polym., 2011, 12, 104-110.
31 F. M. Lu and J. E. Spruiell, The role of crystallization kinetics in the development of the structure and properties of polypropylene filaments, J. Appl. Polym. Sci., 2010, 49, 623631.

32 J. Zimmermann, F. A. Reifler, G. Fortunato, et al., A Simple, One-Step Approach to Durable and Robust Superhydrophobic, Adv. Funct. Mater., 2008, 18, 3662-3669.

$33 \mathrm{H}$. Fashandi and A. R. Ghomi, Developing Breathable Double-Layered Fibrous Membranes Equipped with Water Pulling Mechanism Toward Clothing with Enhanced Comfort, Adv. Eng. Mater., 2017, 1600863.

34 T. Shimoo, K. Okamura and F. Toyoda, Thermal stability of SiO2-coated SiC fiber (Hi-Nicalon) under argon atmosphere, J. Mater. Sci., 2000, 35, 3811-3816.

35 J. W. S. Hearle and A. T. Purdy, The structure of needle punched fabric, Fibre Sci. Technol., 1971, 4, 81-100. 